\title{
Direct Evidence for Daily Plasticity of Electrical Coupling between Rod Photoreceptors in the Mammalian Retina
}

\author{
Nan Ge Jin ${ }^{1}$ and Christophe P. Ribelayga ${ }^{1,2,3,4}$ \\ ${ }^{1}$ Ruiz Department of Ophthalmology and Visual Science, and ${ }^{2}$ Graduate School of Biomedical Sciences, ${ }^{3}$ Program in Neuroscience, Graduate School of \\ Biomedical Sciences, and ${ }^{4}$ Neuroscience Research Center, The University of Texas Health Science Center at Houston, Houston, Texas 77030
}

Rod photoreceptors are electrically coupled through gap junctions. Coupling is a key determinant of their light response properties, but whether rod electrical coupling is dynamically regulated remains elusive and controversial. Here, we have obtained direct measurements of the conductance between adjacent rods in mouse retina and present evidence that rod electrical coupling strength is dependent on the time of day, the lighting conditions, and the mouse strain. Specifically, we show in CBA/Ca mice that under circadian conditions, the rod junctional conductance has a median value of $98 \mathrm{pS}$ during the subjective day and of $493 \mathrm{pS}$ during the subjective night. In C57BL/6 mice, the median junctional conductance between dark-adapted rods is $\sim 140 \mathrm{pS}$, regardless of the time in the circadian cycle. Adaptation to bright light decreases the rod junctional conductance to $\sim 0 \mathrm{pS}$, regardless of the time of day or the mouse strain. Together, these results establish the high degree of plasticity of rod electrical coupling over the course of the day. Estimates of the rod coupling strength will provide a foundation for further investigations of rod interactions and the role of rod coupling in the ability of the visual system to anticipate, assimilate, and respond to the daily changes in ambient light intensity.

Key words: adaptation; circadian clock; electrical coupling; gap junctions; photoreceptors; retina

\section{Significance Statement}

Many cells in the CNS communicate via gap junctions, or electrical synapses, the regulation of which remains largely unknown. Here, we show that the strength of electrical coupling between rod photoreceptors of the retina is regulated by the time of day and the lighting conditions. This mechanism may help us understand some key aspects of day and night vision as well as some visual malfunctions.

\section{Introduction}

Electrical coupling between rod photoreceptors has been extensively explored using both experimental and modeling approaches (Copenhagen and Owen, 1976; Lamb and Simon, 1976; Schwartz, 1976; Detwiler et al., 1978; Werblin, 1978; Attwell and Wilson, 1980; Attwell et al., 1984; Tessier-Lavigne and Attwell, 1988; Hornstein et al., 2005; Zhang and Wu, 2005; Li et al., 2012). Coupling shapes the rod network properties and the light re-

\footnotetext{
Received Sept. 2, 2015; revised Oct. 29, 2015; accepted Nov. 20, 2015.

Author contributions: N.G.J. and C.P.R. designed research; N.G.J. and C.P.R. performed research; N.G.J. and C.P.R. analyzed data; N.G.J. and C.P.R. wrote the paper.

This work was supported by the National Institutes of Health through parent Grant EY018640 (C.P.R.) and vision core Grant EY010608, the Hermann Eye Fund (C.P.R. and Ruiz Department of Ophthalmology) and Research to Prevent Blindness through a Challenge Grant (Ruiz Department of Ophthalmology). We thank Drs Stephen C. Massey and Iris Fahrenfort for critical discussion, Dr Zhijing Zhang for helping with the experiments, Dr Alice Z. Chuang for help with the statistical analysis of the data, and Dr Kimberly A. Mankiewicz for editing the paper.

The authors declare no competing financial interests.

Correspondence should be addressed to Christophe P. Ribelayga, Ruiz Department of Ophthalmology and Visual Science, The University of Texas Medical School, 6431 Fannin Street, MSB 7.024, Houston, TX 77030A. E-mail: Christophe.p.ribelayga@uth.tmc.edu.

DOI:10.1523/JNEUROSCI.3301-15.2016

Copyright $\odot 2016$ the authors $\quad 0270-6474 / 16 / 360178-07 \$ 15.00 / 0$
}

sponse of each rod (Attwell and Wilson, 1980; Attwell et al., 1984; Tessier-Lavigne and Attwell, 1988; Hornstein et al., 2005; Li et al., 2012). Estimates of the rod junctional conductance, a direct measure of the rod-rod coupling strength, range between 0 and $>600$ pS (Zhang and Wu, 2005; Li et al., 2012). A conductance of $\sim 350$ pS or higher is expected to impact human visual performance ( $\mathrm{Li}$ et al., 2012). Thus, rod function depends quantitatively on the extent of electrical coupling (Zhang and Wu, 2005; Li et al., 2012), but whether rod electrical coupling is regulated has long remained a critical unanswered question.

A number of recent studies, including ours, that have used derivative measures of photoreceptor coupling, such as the extent of tracer coupling, globally support a regulation of rod coupling by light and/or a circadian clock, such that coupling may be increased in the dark or at night (Ribelayga et al., 2008; Katti et al., 2013; Li et al., 2013; Jin et al., 2015; Zhang et al., 2015). However, direct evidence that the rod junctional conductance is dynamically regulated is still missing. In addition, the conclusions based on this indirect evidence conflict with theoretical considerations that have proposed that extensive rod coupling at night is expected to degrade the signal-to-noise ratio of single-photon 
events and thus be detrimental to visual performance near absolute threshold (Taylor and Smith, 2004; Okawa and Sampath, 2007).

To resolve this discrepancy, we sought to obtain estimates of the junctional conductance between rods in a well controlled lighting environment and well defined phase in the circadian cycle. We developed a dual perforated patch-clamp technique in mouse based on a technique we recently developed for single-cell recording of mouse rods (Jin et al., 2015). Our direct measurements of the rod junctional conductance demonstrate that rod electrical coupling is regulated on a daily basis such that it is maximal in the dark at night and minimal under bright light adaptation. In addition, we have clarified the dependency of the circadian component on the mouse strain. Thus, rod coupling is dynamically regulated, and our estimation of the amplitude of the regulation indicates that the daily modulation of rod electrical coupling is likely to play a role in rod function and visual performance.

\section{Materials and Methods}

Animals. The care and use of mice were in accordance with federal and institutional guidelines and conducted with the approval of the Institutional Animal Care and Use Committee (The University of Texas Health Science Center Animal Welfare Committee). Two to 6-month-old adult mice of either sex were housed in a $12 \mathrm{~h}$ light/dark cycle (lights on at 7:00 A.M.) for at least 2 weeks before an experiment. We used mice of the following strains: CBA/CaJ (no. 000654) and C57BL/6J (no. 000664; The Jackson Laboratories). Circadian conditions were created by keeping the mice in the dark for up to $36 \mathrm{~h}$, with dark adaptation starting at the end of the light phase (7:00 P.M.). We refer to the subjective day (SD) as the period between circadian time (CT) 0 and CT12 that is, between 12 and $24 \mathrm{~h}$ after the beginning of dark adaptation (SD), and the subjective night (SN) as the period between CT12 and CT24, that is 24 and $36 \mathrm{~h}$ after the beginning of dark adaptation. Based on our previous study (Jin et al., 2015), recordings were made between CT00 and CT06 during the subjective day and between CT16 and CT22 during subjective night, that is at times when rod coupling is expected to be the weakest and the strongest, respectively. Manipulation of the animals and retinal tissue during the night or under circadian conditions was conducted under infrared light with the help of infrared goggles.

Preparation of retinal slices. Dark-adapted mice were anesthetized with a mixture of ketamine and xylazine (100/10 mg/kg, i.m.), decapitated, and one eye was enucleated and rapidly placed in Ames' medium with glutamine buffered with $23 \mathrm{~mm} \mathrm{NaHCO}$ (Sigma-Aldrich). The neural retina was isolated under infrared illumination with dual-unit Prowler Night Vision scopes (Meyers Electro Optics) and placed on a filter paper (0.45 $\mu \mathrm{m}$ HAWP; Millipore). Retinal slices $(250 \mu \mathrm{m})$ were cut with a razor blade tissue chopper (Stoelting) and rotated in the recording chamber to expose the retinal layers. Slices were perfused at $2 \mathrm{ml} \cdot \min ^{-1}$ (turnover $1 \cdot \mathrm{min}^{-1}$ ) with bicarbonate-buffered Ames' solution at $32^{\circ} \mathrm{C}$ continuously gassed with $5 \% \mathrm{CO}_{2} / 95 \% \mathrm{O}_{2}$ to maintain $\mathrm{pH}$ 7.4. Dark adaptation of the retinal tissue was maintained during the slicing procedure. Slices were perfused for $60 \mathrm{~min}$ in the dark or under light-adaptive conditions where indicated, before the start of electrical recording. Chemicals were purchased from Sigma-Aldrich or Fisher Scientific.

Patch-clamp recording of pairs of adjacent rods. Dual-electrode perforated patch-clamp recording of adjacent rods was adapted from the single-electrode technique we previously described that uses $\beta$-escin as the perforating agent (Jin et al., 2015). We found that $\beta$-escin is better for stable long-term perforated patch-clamp recordings of mouse photoreceptors (Jin et al., 2015). Specifically, $\beta$-escin is able to perforate the membrane much faster than amphotericin B ( $<10$ vs $>30$ min; Sarantopoulos et al., 2004; our unpublished observations) and perforation with $\beta$-escin results in minimal access resistance values significantly lower than those after amphotericin B (Sarantopoulos et al., 2004; our unpublished observations). In addition, $\beta$-escin has been shown to preserve receptor-coupled cellular signal transduction mechanisms in smooth muscles (Iizuka et al., 1994; Akagi et al., 1999) and to minimize current run down in neurons (Fan and Palade, 1998; Sarantopoulos et al., 2004; Jin et al., 2015), making it a good alternative ionophore for perforated patch-clamp studies in neurons that can facilitate long-term recordings. Despite having minimal effects on the intracellular medium $\beta$-escin makes holes in the membrane that are large enough to let tracer or dye molecules diffuse into the recorded cell (Fan and Palade, 1998; Jin et al., 2015). Finally, $\beta$-escin does not precipitate and is stable for $>12 \mathrm{~h}$ in solution and is inexpensive compared with amphotericin B or other ionophores. To minimize the dialysis of the recorded cell, we used an intracellular pipette solution rather than a basic perforated patch-clamp solution. The pipette solution contained the following (in $\mathrm{mM}$ ): $10 \mathrm{KCl}$, $120 \mathrm{~K}$-D-gluconate, $5 \mathrm{MgCl}_{2}, 5 \mathrm{Na}_{2}$-ATP, and $1 \mathrm{Na}_{3}$-GTP. The $\mathrm{pH}$ was adjusted to 7.25 with $\mathrm{KOH}$ and osmolarity to $265 \mathrm{mOsm}$. Electrodes were backfilled with $25 \mu \mathrm{M} \beta$-escin (MP Biomedicals) with or without $0.5 \%$ Lucifer yellow (Sigma-Aldrich) in standard electrode solution.

The preparation and electrode tips were visualized with infrared $(>900 \mathrm{~nm})$ differential interference contrast (DIC) microscopy. Two independent micromanipulators (MP285; Sutter Instruments) were used to concomitantly position the two electrodes under visual control. Each electrode was connected to a different amplifier: a 3900A amplifier (Dagan Corporation) or a 200B amplifier (Molecular Devices). Recordings were obtained with using Clampex 10.2 software and digitized with a Digidata 1322A interface (Molecular Devices). Signals were filtered at 1 $\mathrm{kHz}$ with a four-pole Bessel filter and sampled at $1 \mathrm{kHz}$. The two electrodes were fashioned from borosilicate glass capillaries (outer diameter $1.2 \mathrm{~mm}$; inner diameter $0.69 \mathrm{~mm}$; Sutter Instruments) and were identical and contained the same solution. The tip resistance measured in the bath was $10-15 \mathrm{M} \Omega$. The liquid junction potential $(\sim 15 \mathrm{mV})$ was not corrected. The seal resistance ranged from 1 to $20 \mathrm{G} \Omega$. We used positive pressure to give electrode tips clean access to photoreceptor membrane. Following perforation, which typically developed within $10 \mathrm{~min}$, the series resistance was $15-30 \mathrm{M} \Omega$.

Full-field light stimulation was provided by a $175 \mathrm{~W}$ xenon arc lamp (Sutter Instruments). Calibrated neutral density filters and narrow-band interference filters were used to control light density and stimulus wavelength, respectively. Photoreceptors were stimulated with unpolarized monochromatic (500 nm, $10 \mathrm{~nm}$ half-width) light, and the duration of the stimulus was $20 \mathrm{~ms}$. The intensity of the unattenuated stimulus at 500 $\mathrm{nm}$ was $1.62 \times 10^{-2} \mathrm{~W} \cdot \mathrm{cm}^{-2}$ or $8.23 \times 10^{6}$ photons $\cdot \mu \mathrm{m}^{-2} \cdot$ flash $^{-1}$. Following perforation, the identity of the clamped cell was confirmed using a single flash of intensity $8.23-82.3$ photons $\cdot \mu \mathrm{m}^{-2} \cdot$ flash $^{-1}$. When required, light adaptation of the retina was achieved by flashing light $\left(8.23 \times 10^{3}\right.$ photons $\cdot \mu \mathrm{m}^{-2} \cdot$ flash $^{-1} ; 20 \mathrm{~ms}$ flashes at $\left.0.2-2 \mathrm{~Hz}\right)$ for at least $15 \mathrm{~min}$ before recording. The retina was not stimulated during recording of the rod junctional conductance but resumed immediately after. This procedure allowed us to test the effects of the immediate past history of the adaptation state of the retina while eliminating the acute effects of light on membrane conductance during the recordings and minimizing bleaching of the rod photopigment.

To measure electrical conductance between mouse rods, we obtained paired perforated patch-clamp recordings directly from the soma of adjacent rods. The voltage of one rod (slave) was held constant $\left(V_{\mathrm{h}}=-35\right.$ $\mathrm{mV}$ ), and changes in membrane current were measured in response to voltage steps ( $50 \mathrm{~ms}, 10 \mathrm{mV}$ increments from -50 to $+50 \mathrm{mV}$ ) applied to the other rod (driver). A value of the current was taken from the average of the values recorded between 20 and $30 \mathrm{~ms}$ after the beginning of the step. This protocol minimized the influence of voltage-gated channels on the measurements. In particular, holding the driver cell at $0 \mathrm{mV}$ minimized the dark current and activation of the voltage-gated potassium and calcium channels. In addition, we restricted the voltage steps to between -50 and $+50 \mathrm{mV}$ to minimize the activation of the hyperpolarizationactivated current $\left(I_{\mathrm{h}}\right)$, which opens at potentials negative to $-60 \mathrm{mV}$ (Cia et al., 2005; our unpublished observations). Finally, using brief voltage steps minimized the contribution of calcium-activated chloride channels that develop with a time constant of activation $\gg 50 \mathrm{~ms}$ (Cia et al., 2005). A similar approach has been used by others in the field (Zhang and $\mathrm{Wu}$, 2005; Li et al., 2012). The near-perfect linearity of the current-voltage relationship we obtained indicates that the contribution of the voltage- 
A

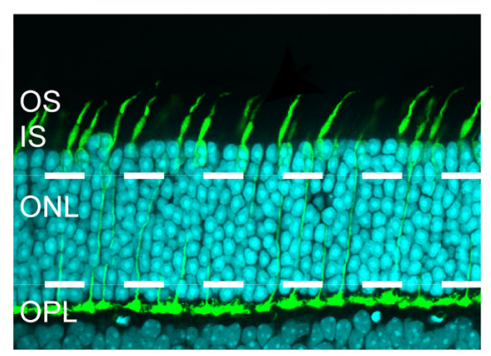

D

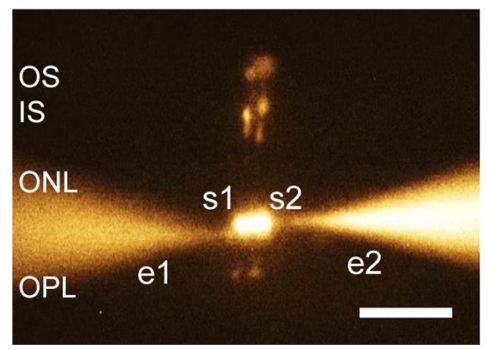

B

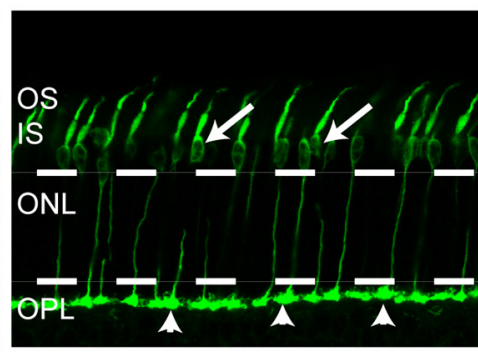

E

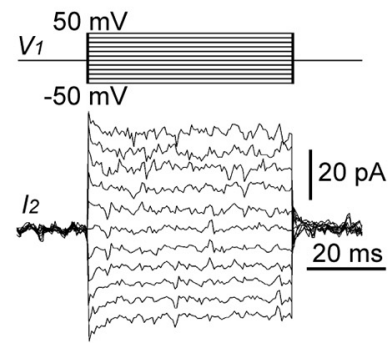

C

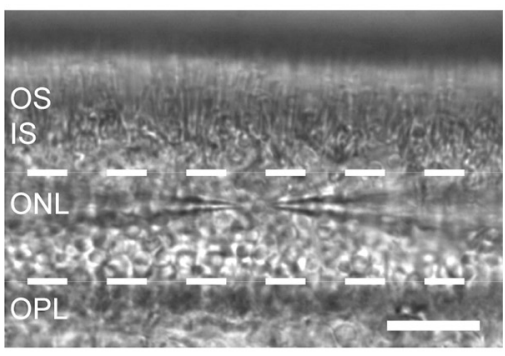

$\mathbf{F}$

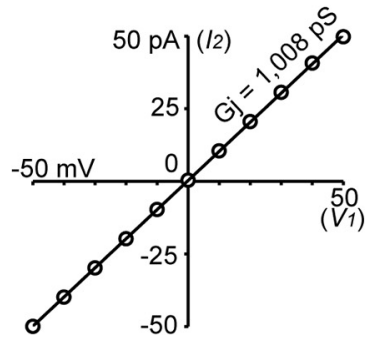

Figure 1. Identification and patch-clamping of rod photoreceptors in the living mouse retinal slice. $A, B, A$ view of the outer portion of a mouse retinal slice fixed in paraformaldehyde, reacted with an antibody against cone arrestin (green), and visualized under a confocal microscope. DAPI staining (blue) of the nuclei is shown in $\boldsymbol{A}$ and omitted in $\boldsymbol{B}$ for clarity. Note the position of the cone somas in the outermost part of the ONL (arrows) and that of the cone pedicles at the bottom of the ONL and in the OPL (arrowheads). Dashed lines delimit the area where rod somas were targeted for recording. OS, Outer segments; IS, inner segments. C, DIC image of the outer portion of a mouse retinal slice and of the recording electrodes placed on adjacent rod somas under infrared ( $>900$ $\mathrm{nm}$ ) illumination, in the experimental setup. $\boldsymbol{D}$, Visualization of a pair of rod somas ( $\mathrm{s} 1$ and s2) simultaneously patch-clamped and filled with Lucifer yellow through the two recoding pipettes (e1 and e2). $\boldsymbol{E}, \boldsymbol{F}$, Simultaneous voltage-clamp recording from a pair of neighboring mouse rods. Shown are junctional currents $\left(I_{2}\right)$ during a series of steps in transjunctional voltage $\left(V_{1} ; \boldsymbol{E}\right)$ and plot of $I_{2}$ as a function of $V_{1}(\boldsymbol{F})$. The transjunctional conductance $(G \mathrm{G})$ is estimated from the slope of the linear regression curve that fits the experimental data. This recording was obtained during the subjective night in a $C B A / C a$ mouse retina. Scale bars: $\boldsymbol{A}-\boldsymbol{C}, 25 \mu \mathrm{m} ; \boldsymbol{D}, 20 \mu \mathrm{m}$.

gated conductances to our measurements was minimal. We checked the linearity of the current-voltage relationship for each recorded pair.

The head stages of our two amplifiers have different resistances ( $1 \mathrm{G} \Omega$ for the Dagan 3900A vs $50 \mathrm{G} \Omega$ for the Axoclamp 200B). We used the $3900 \mathrm{~A}$ to control the driver rod and the $200 \mathrm{~B}$ to measure the transjunctional current in the slave rod. Because of this limitation, we could not directly test the bidirectionality of the transjunctional current by reversing the roles of the driver and the slave cells. However, previous work in salamander (Zhang and $\mathrm{Wu}, 2005$ ) and guinea pig (Li et al., 2012) rods have clearly demonstrated that rod electrical coupling is bidirectional and symmetrical. In addition, if the transjunctional current were to flow preferentially from one cell to the other, for each experimental condition, the distribution of the rod junctional conductance estimates should have been bimodal and this is not what we observed.

In response to voltage steps in the driver cell, we recorded a small ohmic current in the circuit that was not transjunctional and had a maximum amplitude of $5 \mathrm{pA}$ in response to a $50 \mathrm{mV}$ step $(-5 \mathrm{pA}$ in response to a $-50 \mathrm{mV}$ step). This current was independent of the position of the recording electrodes (eg, identical whether the electrodes were 2, 5, or 10 rods apart) and insensitive to the gap junction antagonist meclofenamic acid (Pan et al., 2007; Jin et al., 2015), and was subtracted from the recordings. Our noise-limited detection threshold was thus $\sim 100 \mathrm{pS}$, which is comparable in amplitude to what has been reported by others in the field (for instance, $\sim 40 \mathrm{pS}$; Hornstein et al., 2004).

Immunohistochemistry. Immunohistochemistry of cone arrestin was done as previously described (Liu et al., 2012). The primary antibody was a polyclonal rabbit anti-mouse cone arrestin antibody (Millipore Ab15282; 1/500).

Data analysis. Statistical analyses were performed with Clampfit 10.2 (Molecular Devices) and OriginPro 8.5.1 (OriginLab).

\section{Results}

We recorded the junctional conductance from $>100$ pairs of adjacent rods in mouse retinal slices. Specifically, we performed simultaneous perforated patch-clamp recording of pairs of adja- cent rod somas in living slices of the mouse retina (Fig. 1). Rods represent $\sim 97 \%$ of all somas in the mouse outer nuclear layer (ONL) (Jeon et al., 1998). Conversely, cones represent only 3\% of all somas in the ONL, but they are typically located in the outermost layers of the ONL, where they comprise $\sim 40 \%$ of all somas (Jeon et al., 1998). Also, cone pedicles are located in the innermost rows of the ONL and in the outer plexiform layer (OPL) (Fig. 1 $A, B$ ). We therefore targeted somas in the middle of the ONL where only rod somas are present (Fig. $1 A, B$ ). We positioned the recording electrodes in two directly adjacent somas (Fig. 1C). The identity of rods was confirmed by filling the cells with Lucifer yellow (Fig. 1D) and/or by the low threshold of their light response (Cangiano et al., 2012; Jin et al., 2015). Changes in transjunctional current were linear with voltage, reflecting the ohmic behavior of the rod gap junctions (Fig. 1E,F). The junctional conductance was estimated for each pair from the slope of the transjunctional current-transjunctional voltage relationship (Fig. 1F).

\section{Rod electrical coupling is regulated by time of day in the CBA/ Ca mouse strain}

To determine whether rod electrical coupling is regulated by the time of day, we measured the rod junctional conductance in retinas of the $\mathrm{CBA} / \mathrm{Ca}$ mouse strain at different times in a circadian cycle (see Material and Methods for details). Previous studies have suggested that gap junctional coupling between photoreceptors may be regulated by a circadian clock in this mouse strain so that coupling may be weak during the subjective day and stronger at nighttime (Ribelayga et al., 2008; Jin et al., 2015; Zhang et al., 2015). Animals were dark-adapted for at least $12 \mathrm{~h}$ before surgery and euthanized during the subjective day or the subjective night (see Material and Methods for details). Figure $2 \mathrm{~A}$ 
A

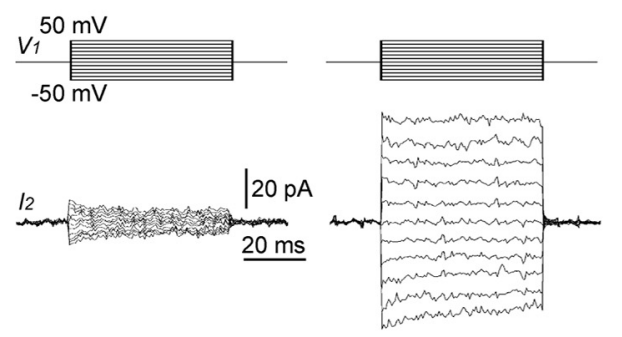

C

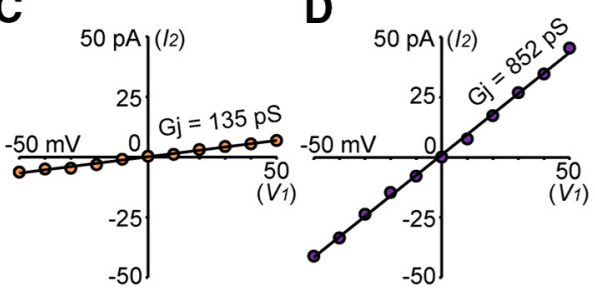

E

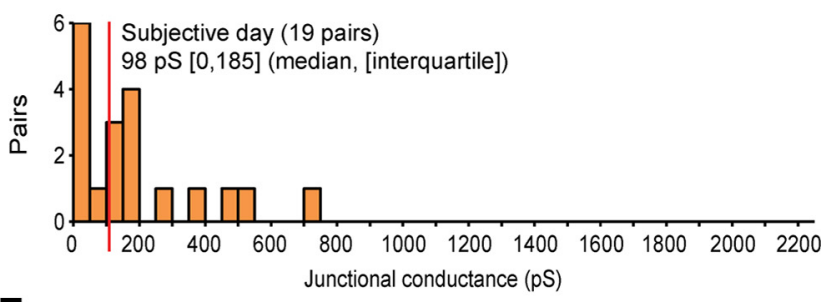

$\mathbf{F}$

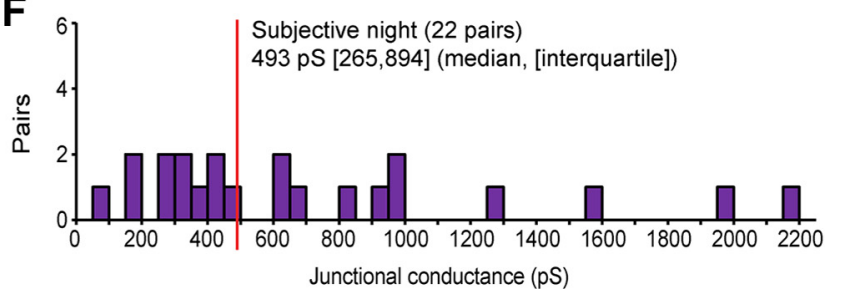

Figure 2. The rod junctional conductance shows a circadian component in the CBA/Ca mouse. Mice were kept dark-adapted for up to $36 \mathrm{~h}$ and euthanized, and their retina collected and processed during the subjective day or the subjective night. $A, B$, Examples of simultaneous perforated voltage-clamp recording from a pair of neighboring mouse rods obtained in a $(B A / C a$ mouse retinal slice during the subjective day $(\boldsymbol{A})$ or subjective night $(\boldsymbol{B}) . \boldsymbol{C}, \boldsymbol{D}$, Plots of transjunctional current as a function of transjunctional voltage for the cells illustrated in $\boldsymbol{A}(\boldsymbol{C})$ and $\boldsymbol{B}(\boldsymbol{D}) . \boldsymbol{E}, \boldsymbol{F}$, Histograms of junctional conductance for rod pairs measured in CBA/Ca mice during subjective day $(\boldsymbol{E})$ or subjective night $(\boldsymbol{F})$. Bin width is $50 \mathrm{pS}$. Red line indicates the position of the median.

A

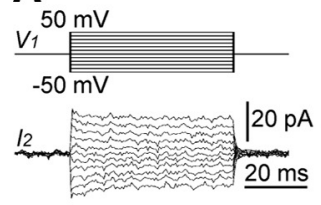

B

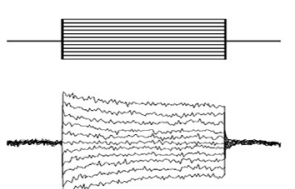

C

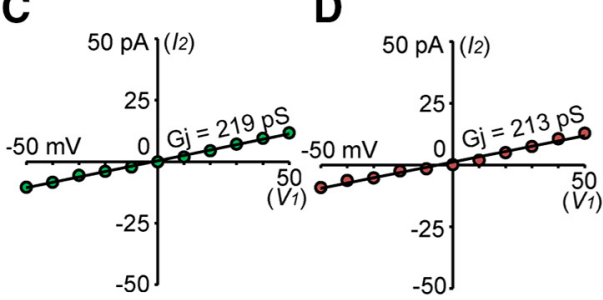

E

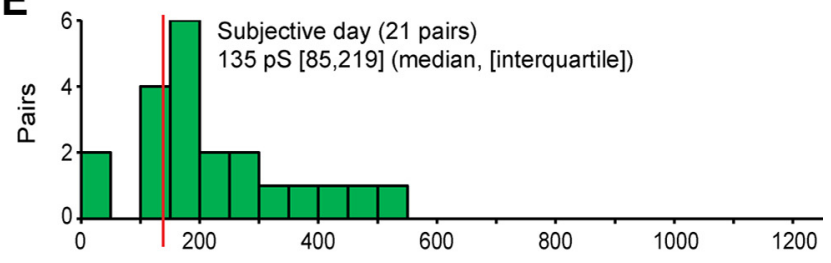

$\mathbf{F}$

Junctional conductance $(\mathrm{pS})$

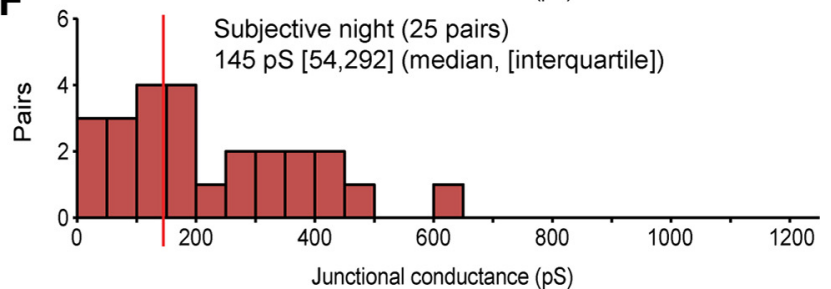

Figure 3. The rod junctional conductance is invariant under dark-adapted conditions in the $C 57 \mathrm{BL} / 6$ mouse. $A, B$, Examples of simultaneous perforated voltage-clamp recording from a pair of neighboring mouse rods obtained in a $57 \mathrm{BL} / 6$ mouse retinal slice during the subjective day $(\boldsymbol{A})$ or subjective night $(\boldsymbol{B})$. C, $\boldsymbol{D}$, Plots of transjunctional current as a function of transjunctional voltage for the cells illustrated in $\boldsymbol{A}(\boldsymbol{C})$ and $\boldsymbol{B}(\boldsymbol{D})$. $\boldsymbol{E}, \boldsymbol{F}$, Histograms of junctional conductance for rod pairs measured in $(57 \mathrm{BL} / 6$ mice during subjective day $(\boldsymbol{E})$ or subjective night $(\boldsymbol{F})$. Bin width is $50 \mathrm{pS}$. Red line indicates the position of the median.

and $C$, illustrates typical recordings of a pair of rods obtained under dark-adapted conditions during the subjective day and the associated current-voltage relationship, respectively. We found estimates of the rod junctional conductance in CBA/Ca retinas during the subjective day ranging from 0 to $705 \mathrm{pS}$ (19 pairs), with a median of $98 \mathrm{pS}[0,185]$ (median, [interquartile]; Fig. 2E). During subjective night, estimates were higher, ranging from 51 to $2154 \mathrm{pS}$ (22 pairs) with a median of $493 \mathrm{pS}[265,894]$ (Fig. $2 B, D, F)$. These data provide direct evidence that the rod junctional conductance is controlled by a circadian clock or time of day in the CBA/Ca mouse retina $(p<0.001$, Kruskal-Wallis one-way ANOVA).

\section{Rod electrical coupling is invariant in the dark in C57BL/6 mice}

Previous studies have suggested that the circadian regulation of photoreceptor coupling may be strain-dependent in mice (Ribelayga et al., 2008; Katti et al., 2013; Li et al., 2013; Jin et al., 2015;
Zhang et al., 2015). For instance, a circadian component of neurobiotin tracer coupling has been found in CBA/Ca mice (Ribelayga et al., 2008) and not in C57BL/6 mice (Li et al., 2013). To determine whether a circadian component in rod electrical coupling exists in the C57BL/6 strain, we measured the rod junctional conductance during the subjective day and the subjective night. During the subjective day, the rod junctional conductance ranged from 0 to $522 \mathrm{pS}$ (21 pairs), with a median of $135 \mathrm{pS}$ $[85,219]$ (Fig. $3 A, C, E$ ). During the subjective night, the rod junctional conductance ranged from 0 to $605 \mathrm{pS}$ ( 25 pairs) with a median of $145 \mathrm{pS}[54,292]$ (Fig. $3 B, D, F)$. The median estimates calculated during the subjective day and the subjective night were not significantly different ( $p=0.834$; Kruskal-Wallis one-way ANOVA). Collectively, these measurements do not support a circadian modulation of rod electrical coupling in C57BL/6 mice; rather, they provide an estimate of $\sim 140 \mathrm{pS}$ for rod electrical coupling strength in C57BL/6 mice under dark-adapted conditions. Thus, these results demonstrate that rod electrical coupling 
A
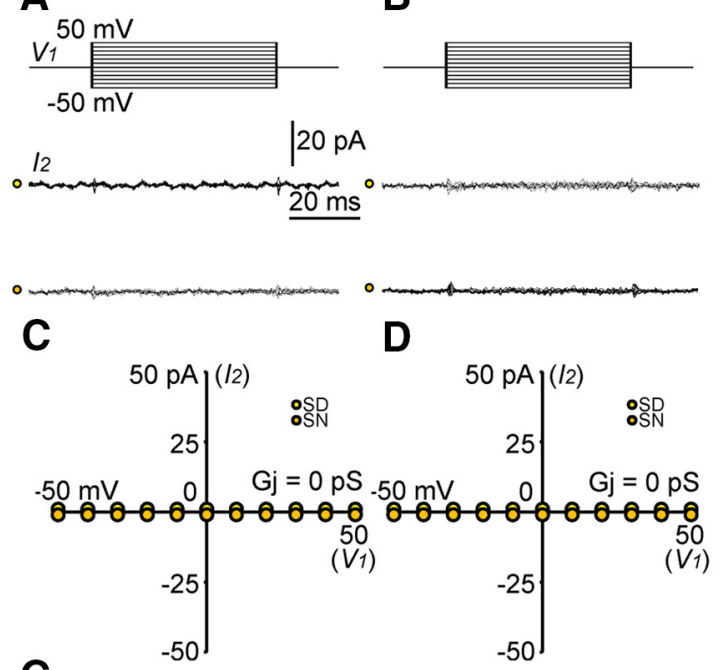

G

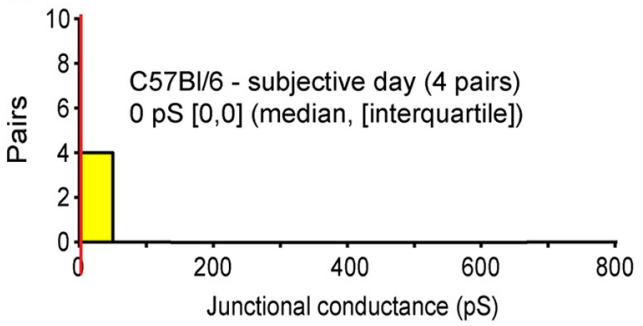

E

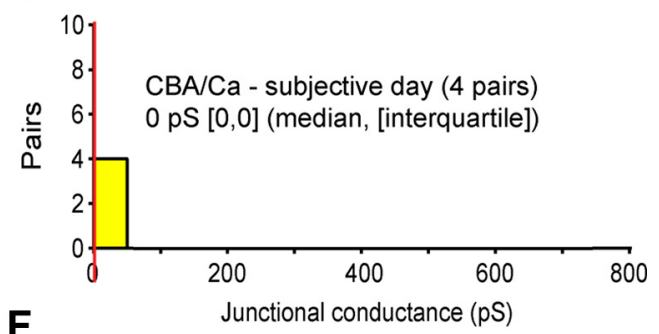

$\mathbf{F}$

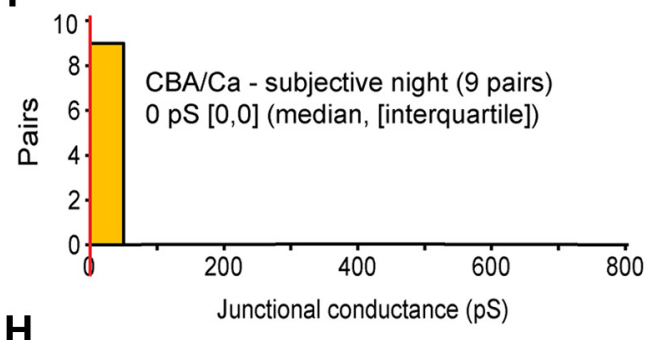

H

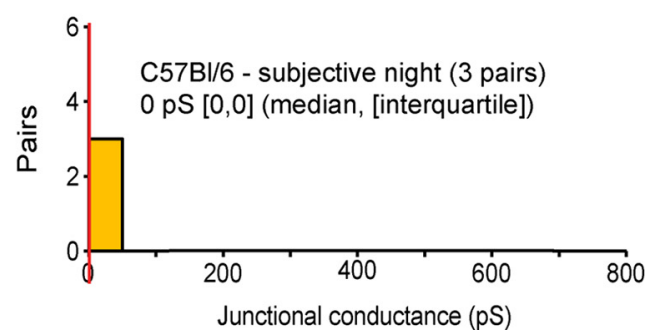

Figure 4. Daylight uncouples rods. $\boldsymbol{A}, \boldsymbol{B}$, Examples of simultaneous perforated voltage-clamp recording from pairs of neighboring rods obtained in a $(B A / C$ a mouse $(\boldsymbol{A})$ and in a $(57 \mathrm{BL} / 6 \mathrm{mouse}$ $(\boldsymbol{B})$ during the subjective day (yellow symbols) or the subjective night (orange symbols) following $>15$ min of bright-light adaptation. $\boldsymbol{C}, \boldsymbol{D}$, Plots of transjunctional current as a function of transjunctional voltage for the cells illustrated in $\boldsymbol{A}(\boldsymbol{C})$ and $\boldsymbol{B}(\boldsymbol{D})$. $\boldsymbol{E}-\boldsymbol{H}$, Histograms of junctional conductance of rod-rod pairs measured in $(B A / C$ a mice $(\boldsymbol{E}, \boldsymbol{F})$ and $\boldsymbol{C} 57 \mathrm{BL} / 6(\boldsymbol{G}, \boldsymbol{H})$ during subjective day $(\boldsymbol{E}, \boldsymbol{G})$ or subjective night $(\boldsymbol{F}, \boldsymbol{H})$. Bin width is $50 \mathrm{pS}$. Red line indicates the position of the median.

does not fluctuate with the time of day in the C57BL/6 mouse strain, in agreement with previous indirect observations (Katti et al., 2013; Li et al., 2013) and in striking difference with what we observed in the CBA/Ca strain (Fig. 2).

\section{Daylight uncouples rods}

To determine whether rod electrical coupling is regulated by ambient light, animals were dark-adapted and retinal tissue collected as described above for the circadian experiments, but retinal slices were exposed to photopic monochromatic light (500 \pm 5 $\mathrm{nm} ; 16.2 \mu \mathrm{W} \cdot \mathrm{cm}^{-2}$ or $8.23 \times 10^{3}$ photons $\cdot \mu \mathrm{m}^{-2} \cdot$ flash $^{-1} ; 20$ $\mathrm{ms}$ flashes at $0.2-2 \mathrm{~Hz}$ ) for at least $15 \mathrm{~min}$ before recording. In both CBA/Ca and C57BL/6 mice, light had a dramatic uncoupling effect on the rods (Fig. 4). Indeed, whether measured during subjective day or subjective night, following bright light adaptation rod junctional conductance was close to $0 \mathrm{pS}[0,0]$ in both $\mathrm{CBA} / \mathrm{Ca}$ [ 4 pairs (subjective day) and 9 pairs (subjective night); Fig. $4 A, C, E, F$ ] and C57BL/6 mice [4 pairs (subjective day) and 3 pairs (subjective night); Fig. $4 B, D, G, H]$. No subjective day/subjective night difference was observed in the two strains $(p=1.0$ in both strains; Kruskal-Wallis one-way ANOVA). Thus, the data demonstrate that bright light uncouples rods regardless of the time of day or the strain, in agreement with previous indirect evidence (Li et al., 2013; Zhang et al., 2015).

\section{Discussion}

Our results establish that the strength of electrical coupling between rod photoreceptors is not constitutive but is dynamically controlled by the time of day and ambient lighting conditions.
Contrary to the theory (Taylor and Smith, 2004; Okawa and Sampath, 2007) but in agreement with derivative measures (Ribelayga et al., 2008; Katti et al., 2013; Li et al., 2013; Jin et al., 2015; Zhang et al., 2015), we demonstrate that rod electrical coupling is weak in daylight, stronger in the dark, and even stronger in the dark at night. In addition, we have clarified that the presence of a circadian component is mouse strain-dependent.

Based on computational models of the mammalian rod network (Hornstein et al., 2005; Li et al., 2012; Jin et al., 2015), it is unlikely that rod coupling $<150 \mathrm{pS}$ plays any major function under scotopic conditions, and thus the strain, lighting conditions, and time of day should all be taken into consideration when studying rod function in mice. But the models also indicate that coupling strength in the range of our higher estimates (493 pS; $\mathrm{CBA} / \mathrm{Ca}$ at night) should have detrimental effects on the signalto-noise ratio of the single-photon response (Hornstein et al., 2005; Li et al., 2012; Jin et al., 2015) and the human absolute threshold (Li et al., 2012). Measurements of the rod singlephoton response in intact CBA/Ca mouse retinas are in agreement with these predictions (Jin et al., 2015). In contrast, strong coupling at night should be beneficial for multiple-photon detection (Hornstein et al., 2005; Li et al., 2012; Jin et al., 2015). We propose that the daily plasticity of rod electrical coupling may represent a mechanism that positions the tradeoff between optimal encoding of single-photon signals and that of multi-photon signals to support the retina's need to process rod signals differently at different times in the daily cycle (Barlow, 2001; Mangel and Ribelayga, 2010). 
There are two major reasons that could explain the broad dispersion of the coupling values at night. First, the broad dispersion could reflect technical limitations. An obvious limitation here is space clamp: incomplete space clamp is expected to introduce more distortion in the current measurements when the cells are coupled compared with when cells are uncoupled. Clamping of the coupled cells could also dialyze important intracellular messengers (eg, cAMP; Li et al., 2013) that may support coupling at night. Slight variations in the access resistance or the integrity of the tissue could affect space clamp and/or dialysis and generate noise in the data. Second, broad dispersion in the data may reflect a particular arrangement of the rod network that is not that of a typical square lattice with each rod contacting all of its closest neighbors. Indeed, previous studies have questioned whether rod coupling is homogenous through the network. Based on electron micrographs of serial sections, Tsukamoto et al. (2001) reported that $\sim 12 \%$ (12/98) of mouse rods may be isolated. Consistent with some rods being isolated, Li et al. (2012) found a bimodal distribution of the estimates of the rod junctional conductance in the guinea pig retina with one-half of the recorded rods (11/22) showing no evidence of coupling (ie, junctional conductance close to $0 \mathrm{pS}$ ) and one-half (11/22) exhibiting a conductance ranging between 195 and $580 \mathrm{pS}$ (with an average of $386 \mathrm{pS}$ ). In the CBA/Ca mouse retina, we found that all pairs of rods $(22 / 22)$ showed evidence of coupling at night in the dark (Fig. $2 F$ ) and none (9/9) under bright light adaptation (Fig. 4F). These data are in agreement with measures of tracer coupling (Jin et al., 2015). Although we cannot rule out that the number of rods coupled to a rod may vary in the matrix, our data do not support the existence of uncoupled rods and further indicate that the regulation of coupling within the network is likely homogeneous. In addition, our own tracer coupling measurements showed that tracer coupled networks of photoreceptors under dark-adapted conditions or at night contain a large proportion of cones, determined to be approximately twice that expected given their abundance in the mouse retina (Li et al., 2013; Jin et al., 2015). Thus, the variability in the measurements of the rod junctional conductance at night may originate from a certain degree of non-uniformity in the pattern of rod coupling to other rods and/or to cones.

Can we quantitatively relate our estimates of the rod junctional conductance to previous measurements of the extent of photoreceptor tracer coupling or the receptive field size of single rods? Although the relationship between tracer coupling and junctional conductance is likely not linear and not straightforward, the spatial distribution of tracer across a patch of coupled cells is nonetheless expected to contract or to expand in response to a reduction or to an increase in gap junction conductance, respectively (Mills and Massey, 1998, see discussion). The low rod junctional conductance we measured here under bright daylight is in agreement with the minimal tracer coupling between mouse photoreceptors measured under similar lighting conditions we previously reported (Li et al., 2013). Similarly, higher estimates of the rod junctional conductance in the dark are in agreement with more extensive tracer coupling between photoreceptors observed in the dark in both C57BL/6 (Li et al., 2013) and CBA/Ca (Ribelayga et al., 2008) mice. Finally, under circadian conditions, the presence of a subjective day/subjective night difference in the rod junctional conductance in CBA/Ca mice and its absence in C57BL/6 are both consistent with the presence of a rhythm in photoreceptor tracer coupling in CBA/Ca (Ribelayga et al., 2008) and its absence in C57BL/6 (Li et al., 2013). Quantitative comparison of the subjective day/subjective night (SD/SN) ratio of the rod junctional conductance to that of the length con- stant of the receptive field of single rods $(\lambda)$ is appropriate because both are a function of the membrane resistance and gap junctional conductance. We reported that in CBA/Ca mice, $\lambda$ is $\sim 5 \mu \mathrm{m}$ during SD and $\sim 14 \mu \mathrm{m}$ during SN (Jin et al., 2015). The length constant can be expressed as follows: $\lambda=\sqrt{ }(R \mathrm{~m} / R \mathrm{~s})$, where $R \mathrm{~m}$ is the membrane resistance and $R \mathrm{~s}$ is the sheet/coupling resistance. Therefore, the ratio $\lambda_{\mathrm{SN}} / \lambda_{\mathrm{SD}}=\mathcal{V}\left[\left(R \mathrm{~m}_{\mathrm{SN}} / R \mathrm{~s}_{\mathrm{SN}}\right) /\right.$ $\left.\left(R \mathrm{~m}_{\mathrm{SD}} / R \mathrm{~s}_{\mathrm{SD}}\right)\right]$. Assuming that $R \mathrm{~m}$ is not significantly different between SD and SN, we can write $\lambda_{\mathrm{SN}} / \lambda_{\mathrm{SD}}=\sqrt{ }\left[G_{\mathrm{SN}} / G_{\mathrm{SD}}\right]$, with $G=$ junctional conductance $=1 / R$. From Jin et al. (2015), $\lambda_{\mathrm{SN}} /$ $\lambda_{\mathrm{SD}} \approx 14 / 5=2.8$. From the values we report here, $G_{\mathrm{SN}} / G_{\mathrm{SD}}=$ $493 / 98=5.0$, and thus $\sqrt{ } 5.0=2.3$. Thus, our estimate of the amplitude of the subjective day/subjective night difference in rod junctional conductance in CBA/Ca mice compares well with the predicted value derived from the measurements of the receptive field size of single rods we previously published (Jin et al., 2015).

The gap junction forming connexin 36 (Cx36) represents the anatomical substrate for electrical coupling between mammalian photoreceptors, although it is still disputed whether $\mathrm{Cx} 36$ is expressed in rods (Bloomfield and Volgyi, 2009; O'Brien et al., 2012). A strong, positive correlation between Cx36 phosphorylation and photoreceptor coupling has been demonstrated in mouse retina: high phosphorylation indicates strong gap junction coupling whereas a dephosphorylated state reflects low coupling (Li et al., 2013). The changes in rod junctional conductance with light adaptation and time of day we report here are globally in agreement with previously published data on the phosphorylation state of Cx36 in mouse photoreceptors. Indeed, Cx36 has been shown to be highly phosphorylated in the dark and poorly phosphorylated in light in photoreceptors in both C57BL/6 (Li et al., 2013) and CBA/Ca (Zhang et al., 2015) strains. In addition, a circadian component in $\mathrm{Cx} 36$ phosphorylation in photoreceptors was evident in CBA/Ca mice (Zhang et al., 2015) but absent or of low amplitude in C57BL/6 mice (Li et al., 2013). Thus, the changes in rod junctional conductance between the different environmental conditions we report here compare well with the prediction from earlier studies.

Although both C57BL/6 and CBA/Ca strains exhibit many robust circadian rhythms such as that of wheel-running activity, the two strains differ in their proficiency to generate circadian rhythms of melatonin (Kasahara et al., 2010; McMahon et al., 2014). Indeed, mutations in the last two enzymes of the melatonin synthesis pathway prevent C57BL/6 mice from increasing melatonin production at night (Kasahara et al., 2010). The absence of a rhythm of melatonin in the retina in turn prevents the occurrence of a circadian rhythm of extracellular dopamine (McMahon et al., 2014), which is a key regulator of photoreceptor coupling (Ribelayga et al., 2008; Li et al., 2013; Jin et al., 2015). The presence of a circadian component in the rod junctional conductance in the CBA/Ca strain and its absence in the C57BL/6 strain we report here are consistent with a key role for the melatonin/dopamine clock pathway in the control of photoreceptor coupling. The results are also consistent with the absence of an intrinsic circadian clock in the rods (Liu et al., 2012; McMahon et al., 2014) that would directly control rod function and further support the importance of neuromodulator rhythms in the control of rod coupling.

In conclusion, our results represent the first formal demonstration, to our knowledge, that electrical coupling between photoreceptors is regulated on a daily basis. Dysfunction in gap junctional communication or circadian signaling has been associated with photoreceptor degeneration (Ripps, 2002; Akopian et al., 2014; McMahon et al., 2014). Estimates of the rod junctional 
conductance will offer a means to further investigate and model photoreceptor interactions in healthy and diseased retinas. Electrical interactions between rods may have to be taken into considerations when designing photoreceptor or retinal implants.

\section{References}

Akagi K, Nagao T, Urushidani T (1999) Responsiveness of beta-escinpermeabilized rabbit gastric gland model: effects of functional peptide fragments. Am J Physiol 277:G736-G744. Medline

Akopian A, Atlasz T, Pan F, Wong S, Zhang Y, Völgyi B, Paul DL, Bloomfield SA (2014) Gap junction-mediated death of retinal neurons is connexin and insult specific: a potential target for neuroprotection. J Neurosci 34: 10582-10591. CrossRef Medline

Attwell D, Wilson M (1980) Behaviour of the rod network in the tiger salamander retina mediated by membrane properties of individual rods. J Physiol 309:287-315. CrossRef Medline

Attwell D, Wilson M, Wu SM (1984) A quantitative analysis of interactions between photoreceptors in the salamander (Ambystoma) retina. J Physiol 352:703-737. CrossRef Medline

Barlow R (2001) Circadian and efferent modulation of visual sensitivity. Prog Brain Res 131:487-503. CrossRef Medline

Bloomfield SA, Völgyi B (2009) The diverse functional roles and regulation of neuronal gap junctions in the retina. Nat Rev Neurosci 10:495-506. CrossRef Medline

Cangiano L, Asteriti S, Cervetto L, Gargini C (2012) The photovoltage of rods and cones in the dark-adapted mouse retina. J Physiol 590:38413855. CrossRef Medline

Cia D, Bordais A, Varela C, Forster V, Sahel JA, Rendon A, Picaud S (2005) Voltage-gated channels and calcium homeostasis in mammalian rod photoreceptors. J Neurophysiol 93:1468-1475. Medline

Copenhagen DR, Owen WG (1976) Coupling between rod photoreceptors in a vertebrate retina. Nature 260:57-59. CrossRef Medline

Detwiler PB, Hodgkin AL, McNaughton PA (1978) A surprising property of electrical spread in the network of rods in the turtle's retina. Nature 274: 562-565. CrossRef Medline

Fan JS, Palade P (1998) Perforated patch recording with beta-escin. Pflugers Arch 436:1021-1023. CrossRef Medline

Hornstein EP, Verweij J, Schnapf JL (2004) Electrical coupling between red and green cones in primate retina. Nat Neurosci 7:745-750. CrossRef Medline

Hornstein EP, Verweij J, Li PH, Schnapf JL (2005) Gap-junctional coupling and absolute sensitivity of photoreceptors in macaque retina. J Neurosci 25:11201-11209. CrossRef Medline

Iizuka K, Ikebe M, Somlyo AV, Somlyo AP (1994) Introduction of high molecular weight (IgG) proteins into receptor coupled, permeabilized smooth muscle. Cell Calcium 16:431-445. CrossRef Medline

Jeon CJ, Strettoi E, Masland RH (1998) The major cell populations of the mouse retina. J Neurosci 18:8936-8946. Medline

Jin NG, Chuang AZ, Masson PJ, Ribelayga CP (2015) Rod electrical coupling is controlled by a circadian clock and dopamine in mouse retina. J Physiol 593:1597-1631. CrossRef Medline

Kasahara T, Abe K, Mekada K, Yoshiki A, Kato T (2010) Genetic variation of melatonin productivity in laboratory mice under domestication. Proc Natl Acad Sci U S A 107:6412-6417. CrossRef Medline

Katti C, Butler R, Sekaran S (2013) Diurnal and circadian regulation of connexin 36 transcript and protein in the mammalian retina. Invest Ophthalmol Vis Sci 54:821-829. CrossRef Medline
Lamb TD, Simon EJ (1976) The relation between intercellular coupling and electrical noise in turtle photoreceptors. J Physiol 263:257-286. CrossRef Medline

Li H, Zhang Z, Blackburn MR, Wang SW, Ribelayga CP, O’Brien J (2013) Adenosine and dopamine receptors coregulate photoreceptor coupling via gap junction phosphorylation in mouse retina. J Neurosci 33: 3135-3150. CrossRef Medline

Li PH, Verweij J, Long JH, Schnapf JL (2012) Gap-junctional coupling of mammalian rod photoreceptors and its effect on visual detection. J Neurosci 32:3552-3562. CrossRef Medline

Liu X, Zhang Z, Ribelayga CP (2012) Heterogeneous expression of the core circadian clock proteins among neuronal cell types in mouse retina. PLoS One 7:e50602. CrossRef Medline

Mangel SC, Ribelayga C (2010) Comparative eye: the circadian clock in the retina regulates rod and cone pathways. In: Encyclopedia of the eye, Vol. 1 (Dartt DA, Besharse JC, Dana R, eds), pp 283-289. Amsterdam: Elsevier AP.

McMahon DG, Iuvone PM, Tosini G (2014) Circadian organization of the mammalian retina: from gene regulation to physiology and diseases. Prog Retin Eye Res 39:58-76. CrossRef Medline

Mills SL, Massey SC (1998) The kinetics of tracer movement through homologous gap junctions in the rabbit retina. Vis Neurosci 15:765-777. Medline

O'Brien JJ, Chen X, Macleish PR, O'Brien J, Massey SC (2012) Photoreceptor coupling mediated by connexin 36 in the primate retina. J Neurosci 32:4675-4687. CrossRef Medline

Okawa H, Sampath AP (2007) Optimization of single-photon response transmission at the rod-to-rod bipolar synapse. Physiology 22:279-286. CrossRef Medline

Pan F, Mills SL, Massey SC (2007) Screening of gap junction antagonists on dye coupling in the rabbit retina. Vis Neurosci 24:609-618. Medline

Ribelayga C, Cao Y, Mangel SC (2008) The circadian clock in the retina controls rod-cone coupling. Neuron 59:790-801. CrossRef Medline

Ripps H (2002) Cell death in retinitis pigmentosa: gap junctions and the "bystander" effect. Exp Eye Res 74:327-336. CrossRef Medline

Sarantopoulos C, McCallum JB, Kwok WM, Hogan Q (2004) Beta-escin diminishes voltage-gated calcium current rundown in perforated patchclamp recordings from rat primary afferent neurons. J Neurosci Methods 139:61-68. CrossRef Medline

Schwartz EA (1976) Electrical properties of the rod syncytium in the retina of the turtle. J Physiol 257:379-406. CrossRef Medline

Taylor WR, Smith RG (2004) Transmission of scotopic signals from the rod to rod-bipolar cell in the mammalian retina. Vision Res 44:3269-3276. CrossRef Medline

Tessier-Lavigne M, Attwell D (1988) The effect of photoreceptor coupling and synapse nonlinearity on signal:noise ratio in early visual processing. Proc R Soc Lond B Biol Sci 234:171-197. CrossRef Medline

Tsukamoto Y, Morigiwa K, Ueda M, Sterling P (2001) Microcircuits for night vision in mouse retina. J Neurosci 21:8616-8623. Medline

Werblin FS (1978) Transmission along and between rods in the tiger salamander retina. J Physiol 280:449-470. CrossRef Medline

Zhang J, Wu SM (2005) Physiological properties of rod photoreceptor electrical coupling in the tiger salamander retina. J Physiol 564:849-862. CrossRef Medline

Zhang Z, Li H, Liu X, O’Brien J, Ribelayga CP (2015) Circadian clock control of connexin36 phosphorylation in retinal photoreceptors of the CBA/ CaJ mouse strain. Vis Neurosci 32:E009. CrossRef Medline 